\title{
The inhibitory effect of MEG3/miR-214/AIFM2 axis on the growth of T-cell lymphoblastic lymphoma
}

\author{
FANG-YI FAN ${ }^{*}$, RUI DENG ${ }^{*}$, HAI YI, HAO-PING SUN, YAN ZENG, GUANG-CUI HE and YI SU \\ Department of Hematology and Hematopoietic Stem Cell Transplantation and Cell Immunotherapy Center, \\ Chengdu Military General Hospital of PLA, Chengdu, Sichuan 610083, P.R. China
}

Received February 24, 2017; Accepted April 21, 2017

DOI: $10.3892 /$ ijo.2017.4006

\begin{abstract}
T-cell lymphoblastic lymphoma (T-LBL) is an aggressive malignancy with poor prognosis and high recurrence rate. Long non-coding RNA (lncRNA)-MEG3 is an important tumor suppressor in various cancers. The present study investigated the potential role of maternally expressed gene 3 (MEG3) in the progression of T-LBL. Suppressed expression of MEG3 was detected in T-LBL tissues compared with adjacent histologically normal tissues. Down-regulated level of MEG3 was also found in three T-LBL cell lines (CCRF-CEM, Jurkat and SUP-T1) compared with human T-cell line H9. The proliferation of T-LBL cells was inhibited and cell apoptosis rate was largely promoted when MEG3
\end{abstract} upregulated by a lentiviral vector. Further research revealed that microRNA (miRNA)-214 is a direct target of MEG3. The expression of miR-214 was increased in T-LBL tissues and cell lines compared with control groups. Besides, decreased level of miR-214 was elevated adding miR-214 mimic in SUP-T1 cells transfected with LncRNA-MEG3. Similarly, upregulated level of miR-214 was downregulated adding miR-214 inhibitor in SUP-T1 cells transfected with MEG3 siRNA. Luciferase activity assay further confirmed the targeting relationship between MEG3 and miR-214. Moreover, AIFM2 protein was

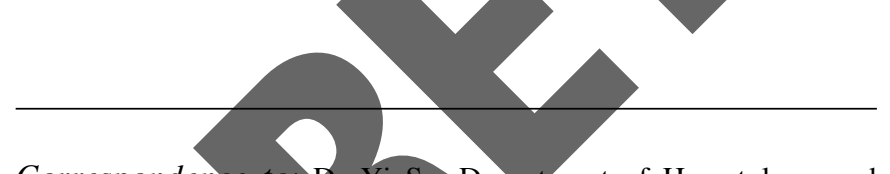

Correspondence to: Dr Yi Su, Department of Hematology and Hematopoietic Stem Cell Transplantation and Cell Immunotherapy Center, Chengdu Military GeneralHospital of PLA, No. 270 Rong Du Avenue, Chengdu, Sichuan 610083, P.R. China

E-mail: suyicdmgh@163.com

*Contributed equally

Abbreviations: T-LBL, T-cell lymphoblastic lymphoma; LncRNAs, long non-coding RNAs; MEG3, maternally expressed gene 3; miRNA, MicroRNA; AIFM2, apoptosis-inducing factor, mitochondrionassociated 2; PCNA, proliferating cell nuclear antigen; siRNA, small interfering RNA; qRT-PCR, quantitative real-time PCR; ARL2, ADP ribosylation factor like 2

Key words: maternally expressed gene 3, miRNA, miR-214, apoptosisinducing factor, mitochondrion-associated 2, T-cell lymphoblastic lymphoma, growth predicted as a target of miR-214. The expression of AIFM2 was increased by MEG3 and was downregulated by miR-214 mimic. miRNA-214 reversed the effect of MEG3 on inhibiting cell proliferation and inducing cell apoptosis and cell cycle arrest in SUP-T1 cells. Moreover, relative expression of AIFM2 had a positive correlation with the expression of MEG3 and was negatively affected by miR-214. In vivo, MEG3 effectively suppressed tumor growth and the expression of proliferation markers Ki-67 and proliferating cell nuclear antigen (PCNA). Taken together, our research revealed that MEG3 worked as an anti-oncogene in T-LBL, and the MEG3-miR-214-AIFM2 pathway regulated the growth of T-LBL, providing potential prognosis markers as well as new potential targets for T-LBL treatment.

\section{Introduction}

Lymphoblastic lymphoma (LBL) is a rare and aggressive malignancy composed of immature B cells belonging to the B-cell lineage (B-LBL) or T-cell lineage (T-LBL) comprised of immature T cells. LBL accounts for $\sim 1-2 \%$ of non-Hodgkin lymphomas (NHL) worldwide, characterized by lymph node enlargement, pleural effusion and mediastinal adenopathy (1). T-LBL, also called a precursor T-cell lymphoblastic lymphoma/leukemia, comprising 80-90\% of all LBL $(2,3)$. T-LBL is typically seen in childhood and young adulthood (average age of onset is 24.5) and affects two to three times as many men as women (4). High recurrence rate in clinic is still a difficult problem due to lack of effective prognostic markers (5). Thus, it is urgent to explore and validate the pathogenesis of T-LBL for more powerful therapeutic methods.

Long non-coding RNAs (LncRNAs), with size larger than $200 \mathrm{nt}$, are a novel class of RNAs regulating multiple biological functions but seldom encoding proteins $(6,7)$. Maternally expressed gene 3 (MEG3), which is an imprinted gene located on chromosome 14q32, has been identified as an important tumor suppressor in various cancers $(8,9)$. Identification of its biological roles is of importance for better understanding the processes of tumorigenesis. A previous study found that MEG3 played regulating role in carcinogenesis and cancer metastasis by interacting with microRNAs, such as miRNA-141 (10), miRNA-148a (11) and miRNA-29 (12) in some cancers. MEG3 was also found 
involved in large B-cell lymphoma (13) and lymphoblastic leukemia (14). However, to date, the regulation mechanism of MEG3 in T-LBL has not been explained clearly.

MicroRNAs (miRNAs or miRs) have been demonstrated as oncogenes or anti-oncogenes to participate in cell differentiation, proliferation and apoptosis by binding to the 3'-untranslated regions (UTR) of messenger RNA, thus, influencing the occurrence and development of tumors and other diseases (15-17). Emerging evidence suggests that miR-214 is often dysregulated during the development and progression in kinds of human cancers, such as breast (18), non-small cell lung cancer (19), including leukemia and lymphoma (20). In a previous investigation, at least two binding sites between MEG3 and miR-214 were found in ovarian cancer (21). In other words, miR-214 has been regarded as a potential biomarker and therapeutic for different cancers, but how it works in T-LBL is still elusive.

Apoptosis inducing factor (AIF), is a caspase-independent oxidoreductase located within the mitochondrial membrane (22). Once activated, AIF causes chromosome condensation and large-scale DNA fragmentation through trans-locating from the mitochondria to the nucleus, thus, inducing nuclear apoptosis $(23,24)$. Apoptosis-inducing factor, mitochondrion-associated 2 (AIFM2), a homologue of AIF, have been proved to induce apoptosis in cancers. For example, activated AIFM2 enhanced apoptosis of human lung cancer cells undergoing toxicological stress (25). Down-regulated expression of AIFM2 was detected in various cancers, including in pediatric acute myeloid leukemia, indicating a anticancer effect $(26,27)$.

In the present study, we explored the mechanism of MEG3 in the proliferation of T-cell lymphoblastic lymphoma. MEG3 was found downregulated in T-LBL tissues and cell lines Elevated MEG3 by exogenous recombinant vector suppressed cell proliferation in vivo and in vitro and induced cell apoptosis. Thus, miR-214 was predicted a target of LncRNA-MEG3, and MEG3 may ameliorate T-LBL through upregulating the expression of AIFM2 by targeting miR-214. The inhibitory effect of MEG3/miR-214/AIFM2 pathway in the proliferation of T-LBT may paye the way for therapeutic targets for T-LBL treatment.

\section{Materials and methods}

Sample collection. A total of 50 pairs of human T-LBL tissues and 38 pairs of adjacent normal tissues were surgically collected from patients in Chengdu Military General Hospital of PLA. The specimens were collected and rapidly frozen in liquid nitrogen and stored at $-80^{\circ} \mathrm{C}$ until use. The study was approved by the Human Ethics Committee/Institutional Review Board of Chengdu Military General Hospital of PLA and was fully informed consent was obtained from all the patients before the sample collection.

Cell lines. The T-LBL cell lines (CCRF-CEM, Jurkat and SUP-T1) and human T-cell line H9 were purchased from the American Type Culture Collection (ATCC; Manassas, VA, USA). All the cell lines were cultured in RPMI-1640 media, (cat. no. 11875-093; Gibco, Carlsbad, CA, USA) supplemented with $10 \%$ fetal bovine serum (FBS; Life Technologies, Inc.,
Grand Island, NY, USA). The cells were grown in humidified air at $37^{\circ} \mathrm{C}$ with $5 \% \mathrm{CO}_{2}$.

Quantitative reverse transcription polymerase chain reaction ( $q R T-P C R)$. Total RNA from related tissues and cell lines was harvested using the TRIzol reagent (Invitrogen, Carlsbad, CA, USA) and was reverse transcribed using RT-PCR kits (Applied Biosystems, Foster City, CA, USA) with an oligo d(T) according to the manufacturer's protocol. The RT-PCR primers for MEG3 and miR-214 were purchased from GeneCopoeia, Inc. (San Diego, CA, USA). The specific primers were as follows: MEG3 (forward, 5'-CCTGCTGCCCATCTACACC TC-3' and reverse, 5'-CCTCTTCATCCTTTGCCATCCT GG-3'); miR-214 (forward, 5'-AGCATAATACAGCAGGCA CAGAC-3 and reverse, 5'-AAAGGTTGTTCTCCACTCTC TCAC-3'). GAPDH was used as the internal control of the mRNA or miRNA, respectively. Fold-change of MEG3 or miR-214 was calculated by the equation $2^{-\Delta \Delta C t}$.

Cell transfection. Mimics/inhibitors specific for miR-214 and LncRNA-MEG3 were designed and purchased from Invitrogen. The mock and fragments were designed as the negative control of miR-214 and UCA1, respectively. The Jurkat and SUP-T1 cells were seeded in 24-well plates at $1 \times 10^{5}$ cells/well. LncRNA-MEG3 and MEG3 scramble was amplified using PrimerSTAR premix (Takara) and cloned into lentivirus plasmid according to the manufacturer's protocol. Jurkat and SUP-T1 cells were transfected with recombinant lentivirus. Mimics/inhibitors specific for miR-214 and mock were transfected into Jurkat and SUP-T1 cells using Lipofectamine 2000 (Invitrogen). Cells were harvested for subsequent experiments after transfection for $24 \mathrm{~h}$.

Cell proliferation assay. Cell proliferation was assayed using the Cell Counting kit-8 (CCK-8; Dojindo Laboratories, Tokyo, Japan) according to the manufacturer's protocol. Firstly, Jurkat and SUP-T1 cells were pretreated with LncRNA-MEG3 or MEG3 scramble. A total of $\sim 5 \times 10^{3}$ Jurkat and SUP-T1 cells were seeded onto 96-well plates and were transfected with LncRNA-MEG3 or MEG3 scramble, respectively. Twentyfour hours later, cells were incubated with CCK-8 solution for $3 \mathrm{~h}$ at $37^{\circ} \mathrm{C}$. Absorbance was determined at $570 \mathrm{~nm}$ using multifunctional microplate reader SpectraMax M5 (Molecular Devices, Sunnyvale, CA, USA) at indicated time-points. All experiments were repeated in triplicate. The cell proliferation trends were depicted according to the absorbance at each time-point.

Northern blot analysis. The expression levels of MEG3 and miR-214 in T-LBL samples, adjacent normal tissues, T-LBL cell lines and human T-cell lines H9 were further determined by Northern blot assay. Northern blot analysis was performed according to the previously described procedures (28).

Western blotting assays. Total protein was extracted from related tissue and cells and then protein concentrations were measured using a Bradford protein assay kit (Bio-Rad Laboratories, Hercules, CA, USA). Equivalent amounts of protein were separated by SDS-PAGE and transferred onto a PVDF membrane (Millipore, Billerica, MA, USA). The 
membranes were blocked in phosphate-buffered saline (PBS) with $0.1 \%$ Tween- 20 containing $5 \%$ non-fat milk for $2 \mathrm{~h}$ at room temperature, and then incubated with the primary antibodies: anti-Ki-67, anti-proliferating cell nuclear antigen (PCNA), anticaspase-3, anti-caspase-9, anti-p27, anti-cyclin A, anti-AIFM2 and anti-GAPDH (Abcam, Cambridge, UK) and the corresponding HRP-conjugated secondary antibodies, followed by detection and visualization using a ChemiDoc XRS imaging system and analysis software (Bio-Rad Laboratories, San Francisco, CA, USA). GAPDH (Abcam) was used as endogenous references.

Cell apoptosis analysis. SUP-T1 cells were seeded in 6-well plates and treated with LncRNA-MEG3 or MEG3 scramble for $24 \mathrm{~h}$. Cell apoptosis were detected by the Annexin V apoptosis detection kit (Beyotime Institute of Biotechnology, Shanghai, China) following a previous study (29). Cell apoptosis percentage was reflected by Annexin V/PI ratio, detected by a flow cytometry (BD Biosciences, Shanghai, China).

Cell cycle analysis. SUP-T1 cells were harvested after $24 \mathrm{~h}$ of treatment with LncR-MEG3 or MEG3 scramble, respectively. After washing with ice-cold PBS, the cells were then harvested and fixed in $70 \%$ ethanol overnight at $4{ }^{\circ} \mathrm{C}$. After that, the cells were washed with PBS, re-suspended in a staining solution containing $20 \mu \mathrm{l}$ RNase A solution and $400 \mu \mathrm{l}$ propidium iodide staining solution (Vazyme Biotech, Co., Ltd., Nanjing, China). Then, cell cycle distribution was assessed using a fluorescence-activated cell sorter (BD FACSCalibur). Results are presented as the pereentage o cells in each phase.

Luciferase activity assay. The full-length 3'-UTR segments of MEG3 mRNA containing the miR-214 binding site was amplfied by chemical synthesis and inserted into the luciferase reporter vector (pGL3) and named MEG3 WT. The mutation of MEG3 in the seed sequence was synthesized using a SiteDirected Mutagenesis kit (Stratagene, La Jolla, CA, USA). Then, $1 \times 10^{6}$ SUP-T1 cells were co-transfected with $0.1 \mu \mathrm{g}$ Luc-MEG3-WT or Luc-MRG3-MUT, together with $40 \mathrm{nM}$ miR-214 mimic/mimic control or 40 nM pGL3 for $24 \mathrm{~h}$ using Lipofectamine 2000. Then luciferase activity was measured using the Dual-luciferase assay system (Promega, Madison, WI, USA) and normalized to Renilla luciferase activity.

Glioma xenografts. Specific pathogen-free (SPF) athymic nude mice (male, 6 to 8 weeks of age) were housed and manipulated according to the protocols approved by the Experimental Animal Center of Chengdu Military General Hospital of PLA. For investigating tumorigenicity of MEG3 in vivo, xenograft mouse model was created by subcutaneous injection of $1 \times 10^{7}$ SUP-T1 cells transfected with LncRNA-MEG3 or MEG3 scramble to SPF nude mice. After development of a palpable tumor, the tumor volume was monitored every 5 days for a month and assessed by measuring the 2 perpendicular dimensions using a caliper and the formula $\left(\mathrm{a} \mathrm{x}^{2}\right) / 2$, where $\mathrm{a}$ is the larger and $\mathrm{b}$ is the smaller dimension of the tumor. Then the mice were sacrificed and the tumor weights were assessed. Tumors from each mouse were randomly selected for immunohistochemical (IHC) analysis. All the animal experiments were performed according to relevant national and international guidelines and were approved by the Animal Experimental Ethical Committee.

Immunohistochemistry. Briefly, $5 \mu \mathrm{m}$-thick paraffinembedded tumor tissue sections were deparaffinized in xylene, rehydrated in graded ethanol gradually and were rinsed twice with PBS. In order to quench the activity of the endogenous peroxidase, the tissue sections were incubated in $30 \% \mathrm{H}_{2} \mathrm{O}_{2}$ for $30 \mathrm{~min}$. After antigen retrieval in heated $10 \mathrm{mM}$ citrate buffer for $10 \mathrm{~min}$, the tissue sections were incubated with mouse anti-human Ki-67 and PCNA primary antibody overnight at $4^{\circ} \mathrm{C}$. Corresponding mouse horseradish peroxidase (HRP)-conjugated secondary antibody was added for $1 \mathrm{~h}$ at room temperature. The images were viewed under a light microscope.

Statistical analysis. The significance of differences between 2 groups was determined by the Student's t-test. All data were expressed as the mean \pm standard deviation (SD) of at least three independent experiments performed in triplicate. All of the P-values were 2-sided and differences were considered statistically significant at $\mathrm{P}<0.05$.

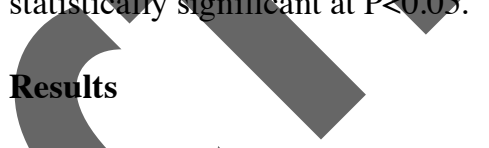

The decreased expression of MEG3 is observed in T-LBL. To investigate the roles of MEG3 in T-LBL, the expression of MEG3 was detected in T-LBL tissues compared with adjacent non-cancer tissues. We found that the level of MEG3 was conspicuously lower in T-LBL tissues compared with normal tissues $(\mathrm{P}<0.01$; Fig. 1A). Besides, the level of MEG3 was significantly decreased in $\mathrm{T}$ lymphocyte leukemia cell lines (CCRF-CEM, Jurkat and SUP-T1) compared with human T-cell line H9 $(\mathrm{P}<0.05, \mathrm{P}<0.01$; Fig. 1B). The expression of MEG3 in the above tissues and cell lines was confirmed by western blot analysis. As shown in Fig. 1C, the result displayed that the expression of MEG3 was strongly suppressed in T-LBL tissues compared with control groups. Similarly, an obvious downregulation of MEG3 was detected in T-LBL cell lines compared to that of T-cell line H9 (Fig. 1D). Collectively, these results suggest that the decreased expression of MEG3 may be involved in the development of T-LBL.

Overexpression of MEG3 suppresses cell growth. To better understand the functional role of MEG3 in T-LBL, we used a lentiviral vector (lv-LncRNA-MEG3) to exogenously upregulate the expression of MEG3. Two T-LBL cell lines, Jurkat and SUP-T1, were used in this experiment. Upregulation of MEG3 in Jurkat and SUP-T1 cells was verified through qRT-PCR ( $<<0.01$; Fig. 2A). Next, CCK-8 assays were performed to detect cell proliferation. The results showed that cell proliferation was significantly inhibited in Jurkat and SUP-T1 cells after transfection with LncRNA-MEG3 lentivirus (Fig. 2B; P<0.01). The expression of proliferation marker proteins Ki-67 and PCNA was also detected. The result exhibited that the level of Ki-67 and PCNA was both restrained by LncRNA-MEG3 transfection (Fig. 2C and D; $\mathrm{P}<0.01)$. The results above indicate that overexpressed MEG3 suppresses cell growth in T-LBL. 
A
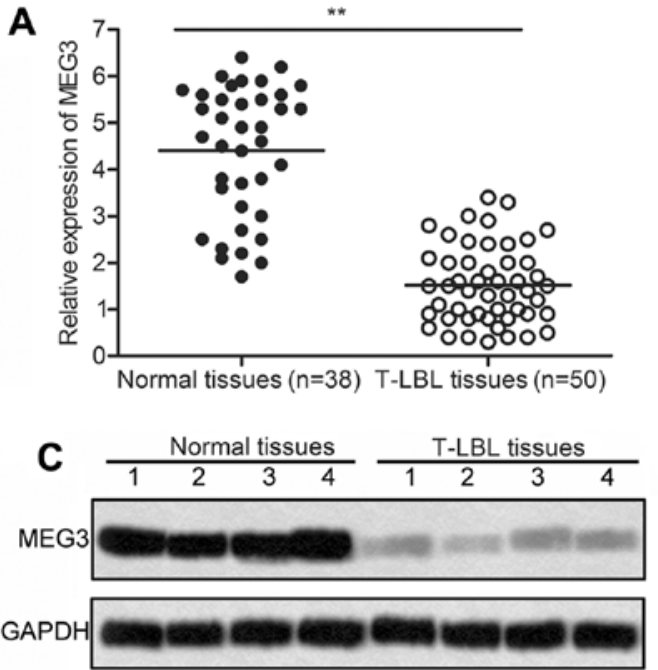

B
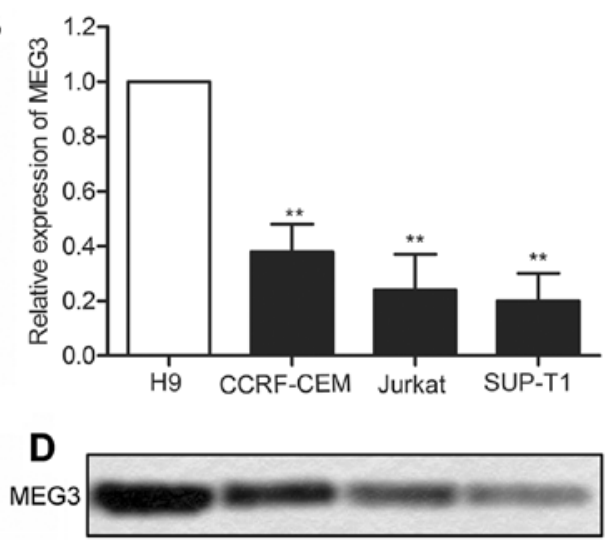

GAPDH

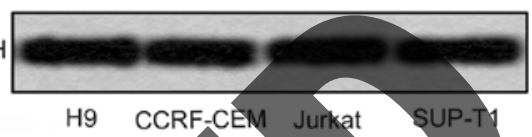

Figure 1. Decreased expression of MEG3 in T-LBL. (A) Relative expression of MEG3 was examined by RRT-PCR in T-LBL samples (n=38) and in adjacent histologically normal tissues ( $\mathrm{n}=50$ ) ( $\mathrm{*} P<0.01$ vs. normal tissues). (B) Relative expression of MEG3 in T-LBL cell lines (CCRF-CEM, Jurkat and SUP-T1) and human T-cell lines $\mathrm{H} 9$ was evaluated through $\mathrm{qRT}-\mathrm{PCR}\left({ }^{* *} \mathrm{P}<0.01\right.$ vs. H9). GAPDH was used as an internal contrøl. (C) Expression of MEG3 in T-LBL tissues and normal tissues was detected through northern blotting. (D) Expression of MEG3 in related T-LBL and normal cell lines was detected through Northern blotting. GAPDH was used as an endogenous reference. The bars show means \pm SD of three independent experiments.

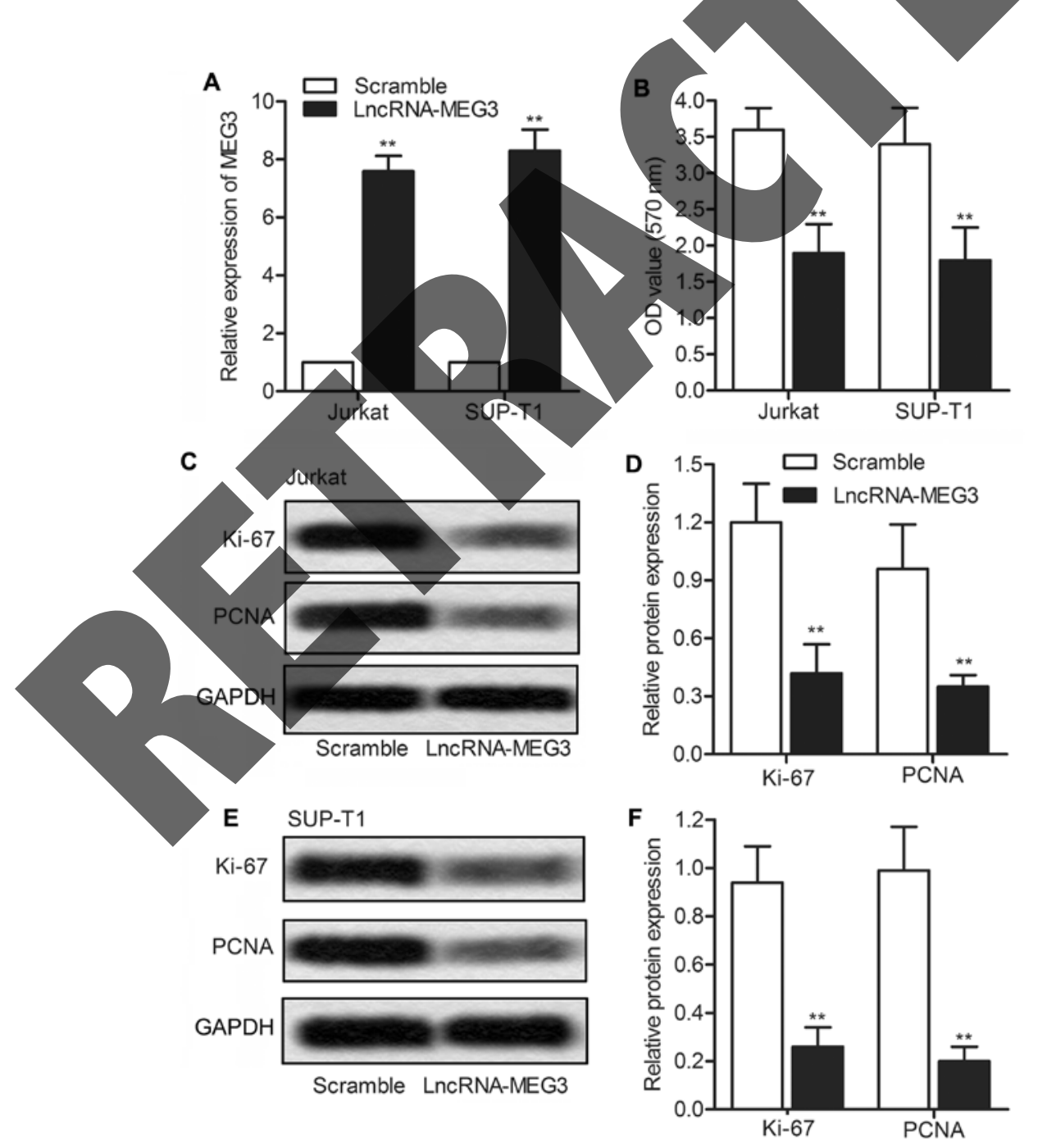

Figure 2. O verexpression of MEG3 suppresses cell growth. Jurkat and SUP-T1 cells were transfected with lv-LncRNA-MEG3 or lv-MEG3 scramble, respectively. (A) Relative expression of MEG3 in Jurkat and SUP-T1 cells was detected through qRT-PCR ("* $\mathrm{P}<0.01$ vs. scramble group). (B) At the indicated time-points, the numbers of cells/well in Jurkat and SUP-T1 cells were measured through CCK-8 assay at $570 \mathrm{~nm}$. The statistical results are shown in the histogram (**P $<0.01$ vs. scramble group). (C and E) The expression of proliferation marker proteins Ki-67 and PCNA in Jurkat (C) and SUP-T1 (E) cells was detected through western blotting. GAPDH was used as an endogenous reference. (D and F) Histograms represent the statistical analysis of western blotting $\left({ }^{* *} \mathrm{P}<0.01\right.$ vs. scramble group). The bars show means $\pm \mathrm{SD}$ of three independent experiments. 
A

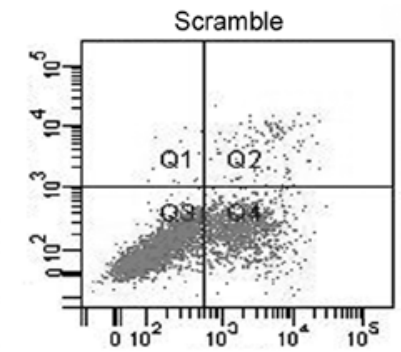

C

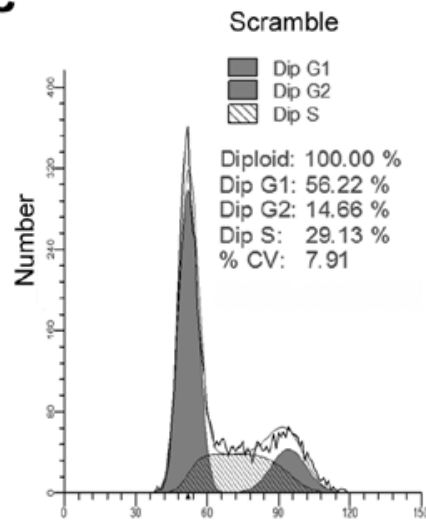

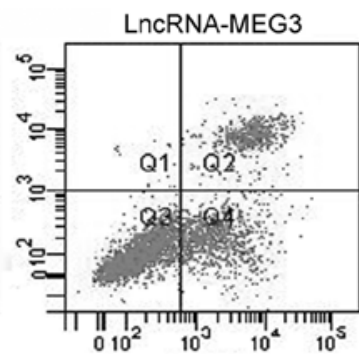

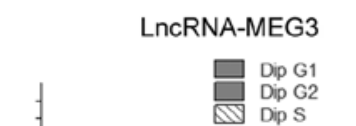

B

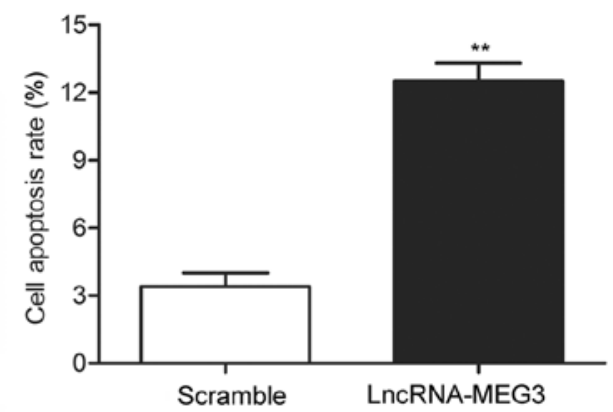

D Diploid: $100.00 \%$ Dip G1: $38.40 \%$ Dip G2: $36.43 \%$ Dip S: $25.16 \%$ \% CV: 9.34

Channels (FL3 LIN-FL3 LIN)

E

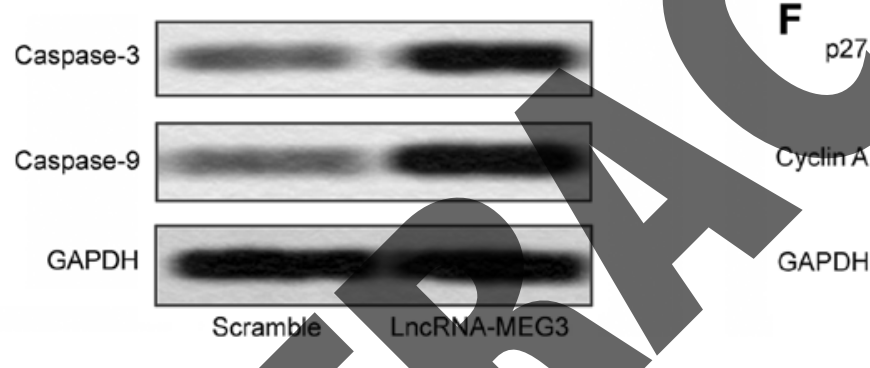

F

G0/G1

$\square S$

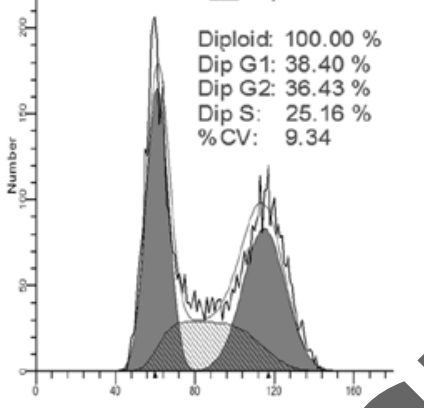

$S$

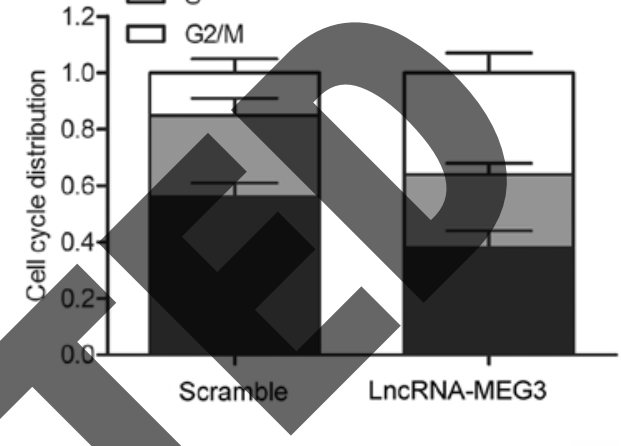

${ }^{227}$
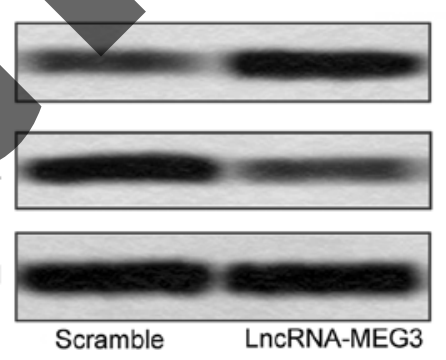

Figure 3. Overexpression of MEG3 induces cell apoptosis and cell cycle arrest. SUP-T1 cells were transfected with lv-LncRNA-MEG3 or lv-MEG3 scramble, respectively. (A) Cell apoptosis was detected using flow cytometry. (B) Histogram represents the statistical analysis of cell apoptosis rate ${ }^{* *} \mathrm{P}<0.01$ vs. scramble group). (C) Cell cycle was examined by flow cytometry, cell number was counted according to DNA content of G0/G1, S and G2/M phases. (D) Histogram represents the statistical analysis of cell cycle arrest. (E) The expression of apoptosis marker proteins caspase-3 and caspase- 9 was detected through western blotting. (F) The expression of cell cycle marker proteins p27 and cyclin A was detected through western blotting. GAPDH was used as an endogenous reference. The bars showed means \pm SD of three independent experiments.

Overexpression of MEG3 induces cell apoptosis and cell cycle arrest. Having established that overexpression of MEG3 suppressed cell growth in T-LBL, flow cytometric analysis was conducted to explore whether MEG3 has a pro-apoptosis effect on T-LBL cells. The results indicated that overexpressed MEG3 markedly promoted tumor cell apoptosis in SUP-T1 cells transfected with lv-LncRNA-MEG3 compared with the scramble group cells (Fig. $3 \mathrm{~A}$ and $\mathrm{B} ; \mathrm{P}<0.01$ ). We further analyzed the effect of MEG3 on cell cycle distribution through flow cytometry in SUP-T1 cells. In comparison with the scramble group cells, lv-LncRNA-MEG3 transfected cell induced an obvious cell cycle arrest in G2/M phase (Fig. 3C and $\mathrm{D} ; \mathrm{P}<0.01)$. The expression of apoptosis-related proteins (caspase-3 and caspase-9) was markedly enhanced under the treatment of LncRNA-MEG3 (Fig. 3E). Moreover, the expression of cell cycle marker protein p27 and cyclin A was detected through western blotting. Upregulated expression of p27 and decreased cyclin A in SUP-T1 cells transfected with lv-LncRNA-MEG3 further identified that overexpressed
MEG3 inhibited cell proliferation (Fig. 3F). The above results demonstrate that overexpressed MEG3 induces cell apoptosis and $\mathrm{G} 2 / \mathrm{M}$ cell cycle progression in T-LBL cell lines.

The level of miR-214 is elevated in T-LBL. Considering the effect of MEG3 overexpression in inhibiting cell viability of T-LBL, we then explored the underlying molecular mechanisms. According to bioinformatics predictions, MEG3 RNA contains the complementary sequences of miR-214 (Fig. 4A). After that, relative expression of miR-214 in T-LBL tissues and cell lines was detected through qRT-PCR and Northern blotting. As shown in Fig. 4B, relative expression of miR-214 was largely upregulated in T-LBL tissues compared with normal tissues. Similarly, remarkable difference was measured between the expression of miR-214 in T-LBL cell lines (CCRF-CEM, Jurkat and SUP-T1) and that in human T-cell lines H9 (Fig. 4C; P<0.01). Additionally, a significantly increased level of miR-214 was found in T-LBL tissues compared with the normal tissues through Northern blotting 


\section{A MEG3 Query 952 GCCTGTCTACACTTGCTGT 970 \\ || || | || || || || || || \\ miR-214 Subject 12 GCCTGTCTACACTTGCTGT 30}

B

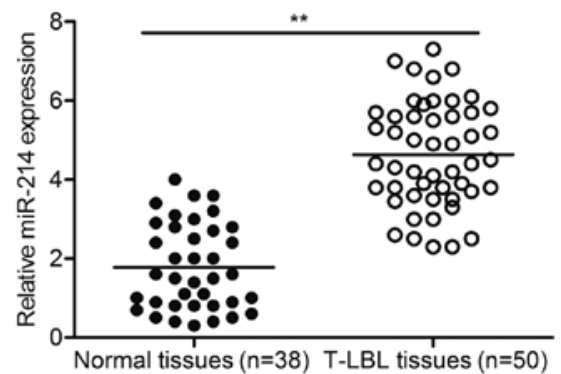

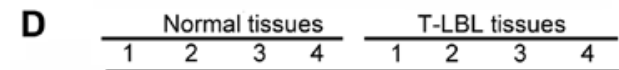

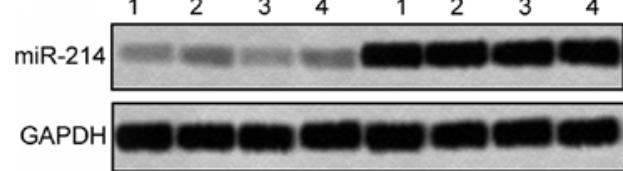

C
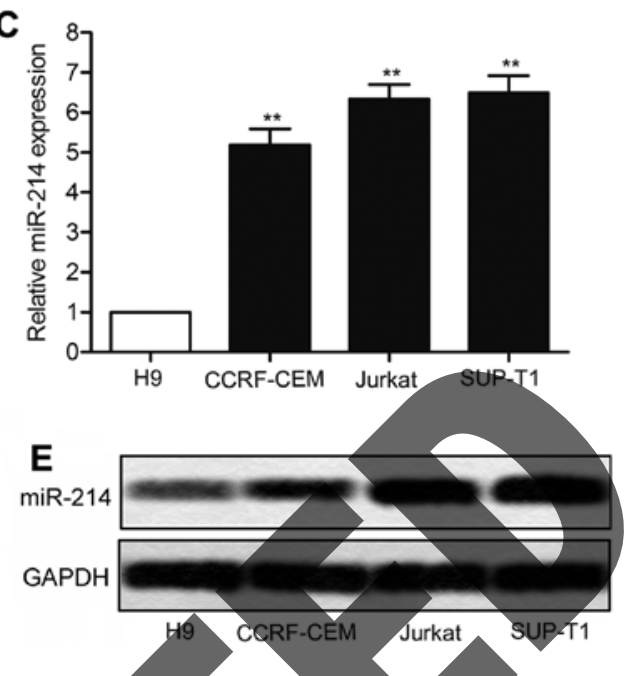

Figure 4. The level of miR-214 was elevated in T-LBL. (A) The targeting relationship between miR-214 and UCA was predicted through bioinformatics. (B) Relative expression of miR-214 in T-LBL tissues $(n=50)$ and normal tissues $(n=38)$ was detected through $\mathrm{qPCR}(* \mathrm{P}<0.01)$. (C) Relative expression of miR-214 in T-LBL cell lines (CCRF-CEM, Jurkat and SUP-T1) and human T-cell line H9 was detected through qRT-PCR ( $\mathrm{P}<0.001$ vs. H9 group). (D) Expression of miR-214 in T-LBL tissues and normal tissues was detected by western blotting. (E) Expression of miR-214 in related cell lines was detected by western blotting. GAPDH was used as an endogenous reference. The bars show means \pm SD of three independent experiments.

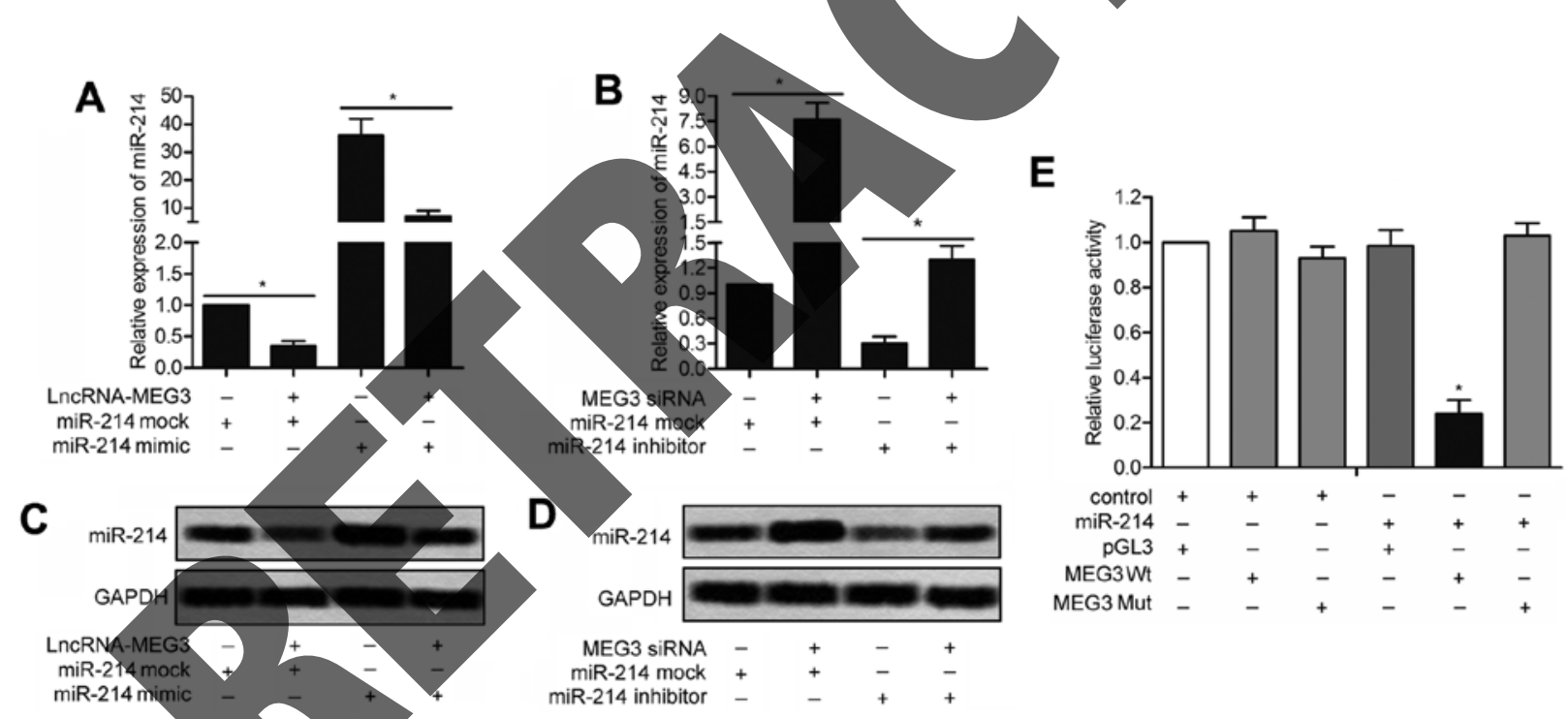

Figure 5. miR-214 is a direct target of MEG3. (A) SUP-T1 cells was transfected with lncRNA-MEG3 and/or miR-135a mock or mimic. Relative expression of miR-214 was detected through qRT.PCR. (B) SUP-T1 cells were transfected with MEG3 siRNA and/or miR-135a mock or inhibitor. Relative expression of miR-214 was detected through qRT-PCR. (C) The expression of miR-214 was measured by western blotting in SUP-T1 cells was transfected with lncRNAMEG3 and/or miR-135a mock or mimic. (D) The expression of miR-214 was measured by western blotting in SUP-T1 cells was transfected with MEG3 siRNA and/or miR-135a mock or inhibitor. GAPDH was used as an endogenous reference. (E) Wild-type (MEG3-WT) or mutant (MEG3-Mut) luciferase reporter and/or miR-214 mimic/pGL3 vetor/mimic control were co-transfected into SUP-T1 cells. The luciferase reporter assay was conducted to detect the luciferase activity in SUP-T1 cells ("P<0.05 vs. MEG3-WT group). The bars show means \pm SD of three independent experiments.

(Fig. 4D). As expected, the expression of miR-214 in related T-LBL cell lines was drastically increased compared with the control cell line (Fig. 4E). All the experiments above reveal that the level of miR-214 is elevated in T-LBL.

miR-214 is a direct target of MEG3. To further assess the potential relationship between miR-214 and MEG3, qRT-PCR and Northern blotting were conducted in SUP-T1 cells transfected with lv-LncRNA-MEG3 or lv-MEG3 siRNA in combination with miR-214 mimic/miR-214 inhibitor/miR-214 mock. As shown in Fig. 5A, the upregulated level of miR-214 in SUP-T1 cells transfected with miR-214 mimic was downregulated by co-transfection with lv-LncRNA-MEG3 $(\mathrm{P}<0.05)$. Similarly, the decreased level of miR-214 was elevated by adding miR-214 inhibitor in SUP-T1 cells transfected with lv-MEG3 siRNA (Fig. 5B; P<0.05). A similar result was 
A

Position 1800-1806 of AIFM2 3' UTR $\quad 5^{\prime}$...UCCCAGUGUGUGAGCGACAGGCC ... 3'

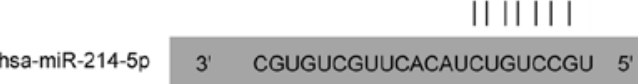
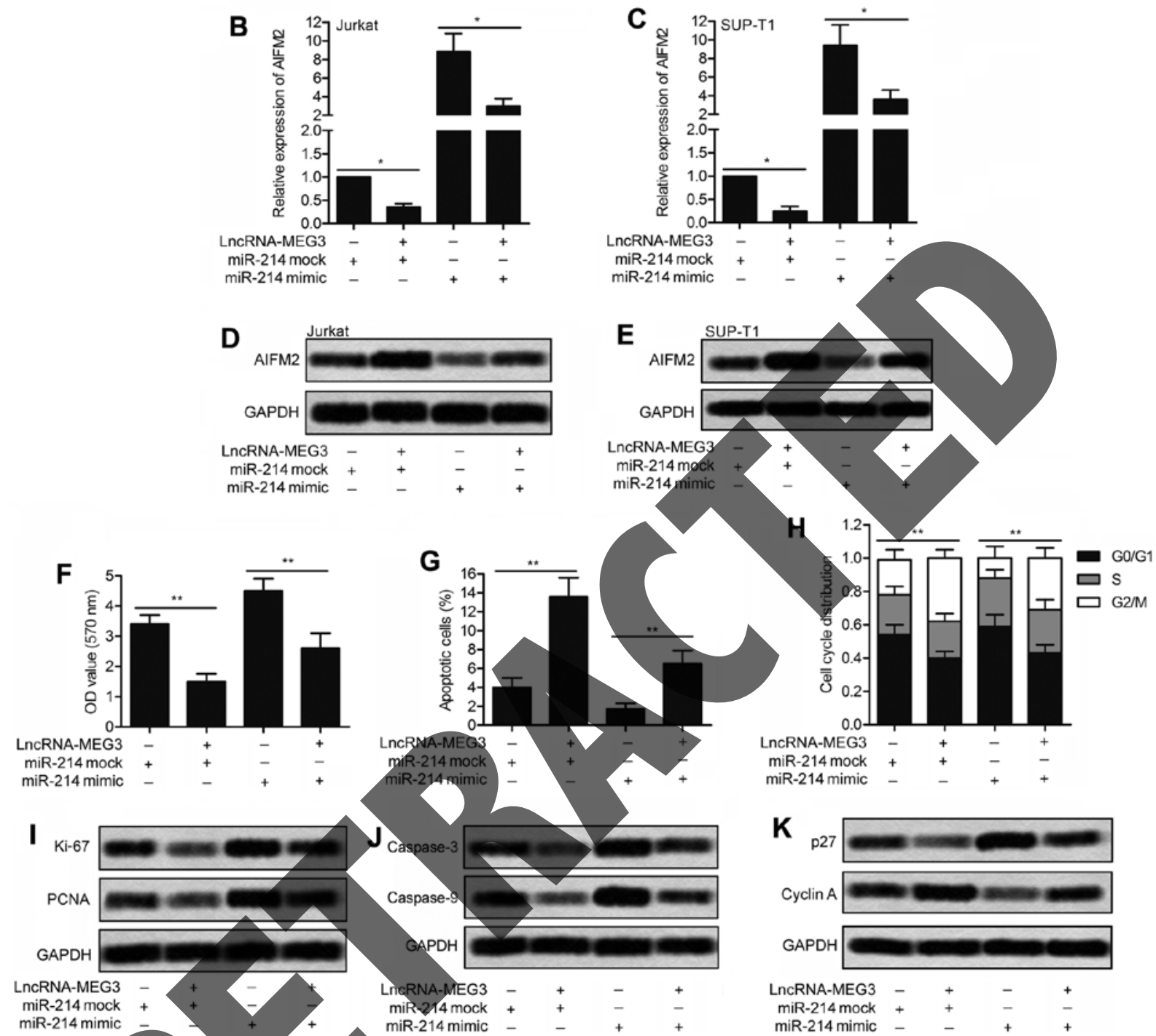

Figure 6. Overexpression of MEG3 upregulates AIFM2. Jurkat and SUP-T1 cells were transfected with lv-LncRNA-MEG3 and/or miR-214 mock/miR-214 mimic. (A) Predicted binding of miR-214 with the 3'-UTR region of AIFM2 mRNA through bioinformatics. (B and C) Relative expression of AIFM2 in Jurkat (B) and SUP-T1 (C) cells was detected through qRT-PCR. (D and E) The expression of AIFM2 in Jurkat (D) and SUP-T1 (E) cells was detected through western blotting. GAPDH was used as an endogenous reference. (F) OD value of SUP-T1 cells was detected through CCK-8 assay at $570 \mathrm{~nm}\left({ }^{* *} \mathrm{P}<0.01\right)$. (G) Flow cytometry was performed to determine the percentage of apoptosis in SUP-T1 cells ( $\left.{ }^{* *} \mathrm{P}<0.01\right)$. (H) The distribution of G0/G1, S and G2/M phases were evaluated in SUP-T1 cells processed in exactly the same way asw mentioned above $\left({ }^{* *} \mathrm{P}<0.01\right)$. (I) The expression of proliferation marker proteins Ki-67 and PCNA in SUP-T1 cells was detected through western blotting. (J) The expression of apoptosis marker proteins caspase-3 and caspase-9 in SUP-T1 cells was detected through western blotting. (K) The expression of cell cycle marker proteins p27 and cyclin A in SUP-T1 cells was detected through western blotting. GAPDH was used as an endogenous reference. The bars show means $\pm \mathrm{SD}$ of three independent experiments.

reflected through Northern blotting. miR-214 mimic reversed the weakening effect of LncRNA-MEG3 on the expression of miR-214 as shown in Fig. 5C. Likewise, the upgrading functions of MEG3 siRNA on the level of miR-214 was weakened by miR-214 inhibitor (Fig. 5D). In addition, the wild-type and mutant 3'-UTR of MEG3 were, respectively, cloned into the luciferase plasmid (pGL3) and co-transfected with miR-214 mimic or miR-214 inhibitor into SUP-T1 cells. The luciferase assay showed that miR-214 mimic effectively inhibited the luciferase activity of the MEG3-WT reporter but that of the
MEG3-Mut reporter was unaffected, suggesting that miR-214 is a direct target gene of MEG3.

Overexpression of MEG3 upregulates AIFM2. The target sequences of miR-214 in the 3'-UTR region of AIFM2 was predicted through bioinformatics analysis (Fig. 6A). In order to further investigate the regulatory relationship between MEG3, miR-214 and AIFM2, Jurkat and SUP-T1 cells were transfected with lv-LncRNA-MEG3 or lv-control and then co-transfected with miR-214 mimic or miR-214 mock. As 

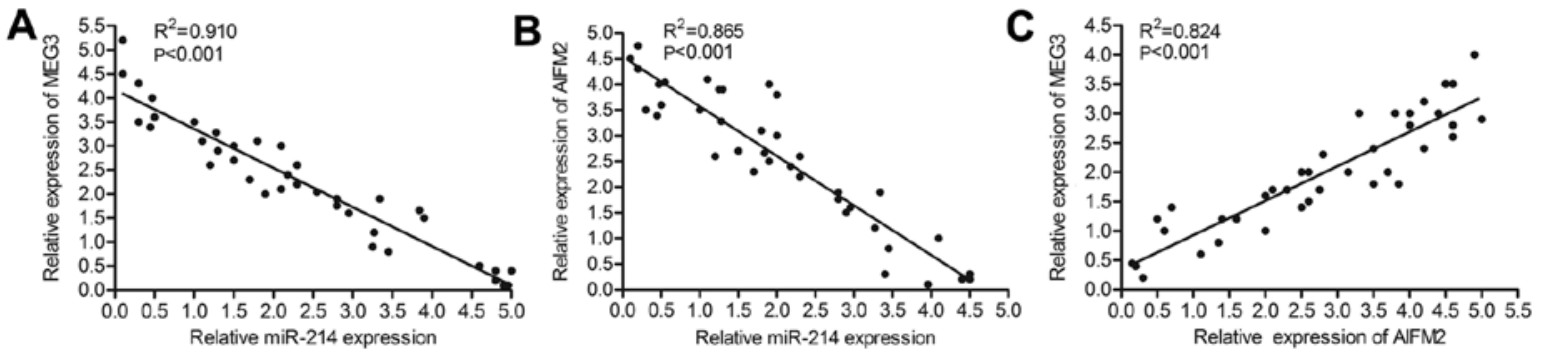

Figure 7. The relationship among the expression of MEG3, miR-214 and AIFM2. (A) The correlation between miRNA-214 and MEG3 in 38 pairs of T-LBL samples, all from Chengdu Military General Hospital, detected through qRT-PCR. (B) The correlation between miRNA-214 and AIFM2 in 38 pairs of T-LBL samples detected through qRT-PCR. (C) The correlation between AIFM2 and MEG3 in 38 pairs of T-LBL samples detected through qRT-PCR.

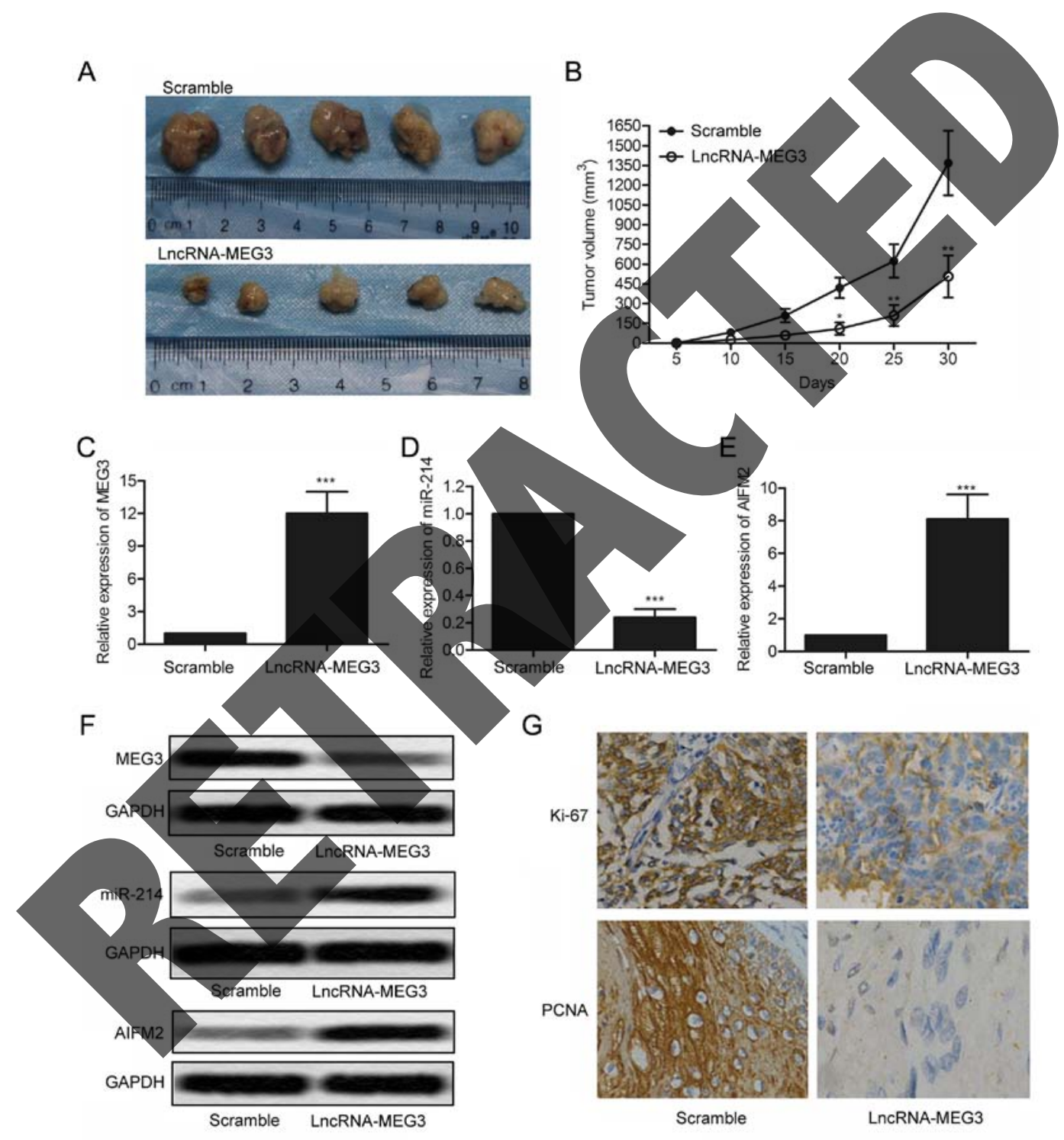

Figure 8. Overexpression of MEG3 inhibits tumor growth in vivo. SUP-T1 cells were transfected with LncRNA-MEG3 or MEG3 scramble and were subcutaneously injected into nude mice. (A) The representative images of T-LBL xenografts are presented (n=5). (B) The diameter of these T-LBL xenografts was periodically measured and tumor growth curve is shown as means \pm SD. (C-E) Relative expression of (C) MEG3, (D) miR-214, (E) AIFM2 in LncRNA-MEG3 group and MEG3 scramble group was detected through qRT-PCR ( ${ }^{* * *} \mathrm{P}<0.001$ vs. scramble group). (F) The expression of MEG3, miR-214 and AIFM2 in LncRNA-MEG3 group and MEG3 scramble group was detected through western blotting. (G) Expression of proliferation marker proteins Ki-67 and PCNA in formalin-fixed, paraffin-embedded tumors from scramble or LncRNA-MEG3 group mice was detected through IHC analysis.

shown in Fig. 6B and C, the RNA level of AIFM2 was strongly upregulated by MEG3 and was suppressed by miR-214 detected through qRT-PCR $(\mathrm{P}<0.05)$. Similarly, the result of western blotting exhibited that the levels of AIFM2 in Jurkat and SUP-T1 cells was significantly elevated by MEG3 and was reduced by miR-214 (Fig. 6D and E). 
Furthermore, the impact of miR-214 on cell proliferation, cell apoptosis and cell cycle was adverse to that of MEG3. Compared with the miR-214 mock group, cell proliferation was promoted by miR-214 mimic and the facilitating role was weakened by MEG3 (Fig. 6F; P $<0.01$ ). Moreover, the increased cell apoptosis rate by MEG3 was downregulated by co-transfecting with miR-214 mimic in SUP-T1 cells (Fig. 6G; $\mathrm{P}<0.01$ ). Compared with the control group, cell cycle was arrested in G2/M phase by MEG3 and the regulating role was abolished by miR-214 mimic (Fig. $6 \mathrm{H} ; \mathrm{P}<0.01$ ).

The expression of related proteins in SUP-T1 cells was detected through western blotting. Compared with the control group, the level of proliferation marker proteins $\mathrm{Ki}-67$ and PCNA was inhibited by MEG3 and was elevated by miR-214 mimic (Fig. 6I). As expected, the level of apoptosis marker proteins (caspase-3 and caspase-9) was enriched by MEG3 and was decreased by miR-144 mimic (Fig. 6J). The opposite effect on the regulation of cell cycle marker proteins p27 and cyclin A was seen between miR-214 and MEG3 through western blotting (Fig. 6K). Taken together, our results above reveal that AIFM2 is upregulated by MEG3 by targeting miR-214.

The relationship among the expression level of MEG3, miR-214 and AIFM2. Knowning that the level of AIFM2 was upregulated by MEG3 and was suppressed by miR-214 in T-LBL cell lines, further research was conducted to explore the relationship among the expression level of MEG3, miR-214 and AIFM2 in T-LBL tissues. RNA was extracted in T-LBL tissues donated from Chengdu Military General Hospital of PLA ( $n=38)$. Relative expression of MEG3, miR-214 and AIFM2 was detected through qRT-PCR. As shown in Fig. 7A and $\mathrm{B}$, the expression of miR-214 varied inversely with the expression of MEG3 and AIFM2, r

tive expression of AIFM2 was p tive expression of AIFM2 was positively related to the lever of MEG3 (Fig. 7C). Thus, we conclude that the expression of AIFM2 was upregulated by MEG3 and was downregulated by $\mathrm{miR}-214$ in vivo.

Overexpression of MEG3 inhibits tumor growth in vivo. We then set out to explore the effect of exogenous MEG3 over-expression on T-LBL in vivo. SUP-T1 cells were transfected with IV-LncRNA-MEG3 or lv-scramble for $24 \mathrm{~h}$. Then, the cells were collected and inoculated into female athymic nude mice subcutaneously. Average tumor volume in LncRNA-MEG3 group was much smaller than the scramble group (Fig. 8A and B). In order to investigate the effect of MEG3 on the expression of miR-214 and AIFM2 in vivo, qRT-PCR and western blotting were separately conducted on SUP-T1 cells transfected with lv-LncRNA-MEG3 or lv-scramble. The relative expression level of MEG3 and AIFM2 was largely increased by LncRNA-MEG3 (Fig. 8C and E). By contrast, the expression of miR-214 was apparently suppressed by LncRNA-MEG3 (Fig. 8D). Consistent with this, the western blotting results exhibited that overexpressed MEG3 raised the expression of AIFM2 and reduced the level of miR-214 (Fig. 8F). Moreover, the upregulated expression of proliferation marker protein Ki-67 and PCNA in LncRNA-MEG3 group also verified that MEG3 promoted cell proliferation in T-LBL (Fig. 8G). Based on the above results, we deduce that overexpressed MEG3 inhibits tumor growth in vivo.

\section{Discussion}

T-cell lymphoblastic lymphoma is an aggressive malignancy and ranks the second most common subtype of non-Hodgkin lymphoma in children. Due to the lack of adequate understanding of the pathogenesis and genetic change of T-LBL, it is difficult to carry out a targeted and effective therapeutic method, so high risk of recurrence and worse overall survival have always been difficult problems in T-LBL treatment (30). In a previous study, MEG3 was identified to be involved in multiple physical functions and diseases. However, little is known about the roles and mechanisms of MEG3 in T-LBL process. In the present study, we presented a new perspective that MEG3 participated in the regulation of T-LBL proliferation and apoptosis through the MEG3-miR-214-AIFM2 pathway.

The present studies established that the expression of MEG3 was found universally downregulated human primary tumors, including $25 \%$ of neuroblastomas (31), $81 \%$ of hepatocellular cancers (12) and $82 \%$ of gliomas (32). For example, downregulation of MEG3 was associated with poor prognosis and repressed the proliferation, clone formation and induced apoptosis in glioma cells (33). Furthermore, downregulation of MEG3 in cancer has a close relationship with tumor grade (34). According to cytogenetic studies, abnormalities of chromosome 14 , including $14 \mathrm{q} 32$, is found more frequently in higher grade cancers (35). Thus, the low expression of MEG3 has become a biomarker for an increased risk of metastasis and a poor prognosis in cancer treatment. As expected, downregulated expression of MEG3 was found in T-LBL tissues and related cell lines compared with normal tissues and cell lines. The results suggest that the suppressed expression of MEG3 is involved in the pathogenesis of T-LBL.

Emerging evidence has identified that MEG3 acts as tumor suppressor in various cancers. For example, Zhang et al (36) reported that downregulated MEG3 suppressed proliferation and promoted apoptosis by regulating miR-21 in cervical cancer. Others pointed out that suppressed MEG3 inhibited proliferation, migration and invasion by depending on the p53 transcriptional activity in breast cancer (37). Similarly, in the present study, decreased cell proliferation and elevated cell apoptosis were measured after transfecting lv-LncRNAMEG3 into T-LBL cell lines. Previous studies revealed that downregulated MEG3 induced cell cycle arrest in lung cancer (38), nasopharyngeal carcinoma (39) and human hepatoma (40). In accordance with these investigations, we found that an obvious cell cycle arrest in G2/M phase was induced by LncRNA-MEG3 in T-LBL cell lines. Upregulated expression of p27 and decreased level of cyclin A in SUP-T1 cells transfected with lv-LncRNA-MEG3 further identified that overexpressed MEG3 inhibited proliferation of T-LBL in vitro. The results above demonstrate that overexpressed MEG3 restrains cell proliferation and promotes cell apoptosis in T-LBL cell lines.

MiRNAs have been identified to play regulating roles in various cellular pathological processes. Previous research evidenced that miR-214 suppressed growth and invasion of 
cervical cancer cells by downregulating ADP ribosylation factor like 2 (ARL2) (41). Others demonstrated that miR-214 was downregulated in breast cancer and served as a novel tumor suppressor through inhibiting WNT signaling by direct repression of $\beta$-catenin (42). However, miR-214 has also been suggested as an oncogene in some diseases, such as osteosarcoma (43) and gastric cancer (44). In recent reports, the expression of miR-214 was found upregulated in T-cell lymphoma and overexpressed miR-214 acted as diagnostic/ prognostic biomarkers in T-cell lymphoma (45). Similarly, upregulated level of miR-214 was detected in T-LBL tissues and related cell lines compared with normal tissues and cell lines. According to previous reports, miRNAs negatively influenced their target genes by binding to target mRNA transcripts of protein-coding genes specifically. Sharma et al (46) demonstrated that the combination of miR-214 and 3' untranslated regions (UTR) of target mRNAs led to inhibition of protein production in cancers. In agreement with these reports, miR-214 was predicted as a target of MEG3 through bioinformatics analysis in this study. Besides, the level of miR-214 was elevated adding miR-214 mimic in SUP-T1 cells transfected with LncRNA-MEG3. Similarly, upregulated level of miR-214 was downregulated adding miR-214 inhibitor in SUP-T1 cells transfected with MEG3 siRNA. Luciferase reporter assays showed that miR-214 mimic largely reduced the fluorescence signal by binding with the 3'-UTR of MEG3 Wt. The results above revealed that miR-214 is a direct target of LncR-MEG3.

AIFM2 was reported significantly associated with fatig in prostate cancer patients during receiving external beam radiation therapy (47). The DNA binding activity of AIFM2 contributed to the onset of apoptosis in human colon cancer cell lines (48). However, the regulating role of AIFM2 in T-LBL is still elusive. Previous studied validated that the accumulation of MEG3 induced a significant increase of $\mathrm{p} 53$ protein in human cancer cells (49) and then upregulated p53 to regulate the transcription of AIFM2 (50). These studies prompted us to further explore the relationship between MEG3 and miR-214 and their involyement in AIFM2 of T-LBL. In the present study, the potential targeting relationship between AIFM2 and miR-214 was predicted through bioinformatics analysis. Further research proved that the expression of AIFM2 in T-LBL cells was upregulated by MEG3 and was abated by $\mathrm{miR}-214$. Then, $\mathrm{CCK}-8$ assay and flow cytometry showed that miR-214 reversed the regulating role of MEG3 on inhibiting cell proliferation and inducing cell apoptosis and cell cycle arrest. Moreover, relative expression of miR-214 varied inversely with the expression of MEG3/AIFM2 and the level of AIFM2 was positively related to MEG3. All the results presented above reveal that MEG3 upregulates the level of AIFM2 by targeting miR-214.

Having identified that LncR-MEG3 inhibited the proliferation of T-LBL in vitro, we further explored the effect of LncR-MEG3 in vivo. According to previous reports, MEG3 was identified to regulate tumor growth in various cancers such as prostate cancer (51), human pituitary tumor (52) and pancreatic cancer (53). In the present study, upregulated LncR-MEG3 significantly suppressed tumor growth and tumor volume in LncR-MEG3 model mice. Besides, MEG3 suppressed the expression of miR-214 and raised the level of AIFM2 in vivo. Moreover, the expression of proliferation markers (Ki-67 and
PCNA) was controlled by LncRNA-MEG3 detected through immunohistochemistry. The results above demonstrate that MEG3 depresses cell proliferation in vivo.

In conclusion, our research found that the expression of MEG3 was suppressed in T-LBL tissues and cell lines. Upregulated MEG3 by transfection suppressed cell proliferation and promoted cell apoptosis in vitro. Further research revealed that miR-214 was a direct target of MEG3. MEG3 was verified to restrain the proliferation of T-LBL by sponging miR-214 to upregulate the expression of AIFM2. Moreover, MEG3 was identified to suppress T-LBL growth in vivo. In summary, the MEG3-miR-214-AIFM2 pathway may serve as potential prognosis marker and new target for cancer therapy.

\section{Acknowledgements}

The present study was funded by the project of Young Talent Reserve of Chengdu Military Region General Hospital (no. 2016kc40).

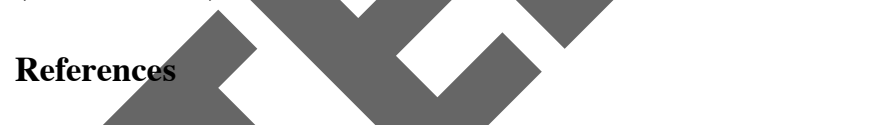

1. Armitage JO and Weisenburger DD: New approach to classifying non-Hodgkin's lymphomas: Clinical features of the major histologic subtypes. Non-Hodgkin's Lymphoma Classification Project. J Clin Oncol 16: 2780-2795, 1998.

No authors listed: A clinical evaluation of the International Lymphoma/Study Group classification of non-Hodgkin's lymphoma. The Non-Hodgkin's Lymphoma Classification Project. Blood 89: 3909-3918, 1997.

Park HS, McIntosh L, Braschi-Amirfarzan M, Shinagare AB and Krajewski KM: T-cell non-Hodgkin lymphomas: Spectrum of and the role of imaging in the management of common subtypes. Korean J Radiol 18: 71-83, 2017.

Han X, Kilfoy B, Zheng T, Holford TR, Zhu C, Zhu Y and Zhang Y: Lymphoma survival patterns by WHO subtype in the United States, 1973-2003. Cancer Causes Control 19: 841-858, 2008.

5. Chang MH, Kim SJ, Kim K, Oh SY, Lee DH, Huh J, Ko YH, Choi CW, Yang DH, Won JH, et al: Clinical features and treatment outcomes of adult B- and T-lymphoblastic lymphoma: Results of multicentre analysis in Korea. Leuk Lymphoma 50: 1119-1125, 2009.

6. He Y, Meng XM, Huang C, Wu BM, Zhang L, Lv XW and Li J: Long noncoding RNAs: Novel insights into hepatocellular carcinoma. Cancer Lett 344: 20-27, 2014.

7. Li CH and Chen Y: Targeting long non-coding RNAs in cancers: Progress and prospects. Int J Biochem Cell Biol 45: 1895-1910, 2013.

8. Benetatos L, Vartholomatos $\mathrm{G}$ and Hatzimichael E: MEG3 imprinted gene contribution in tumorigenesis. Int J Cancer 129: 773-779, 2011.

9. Zhang X,Zhou Y,Mehta KR, Danila DC,Scolavino S, Johnson SR and Klibanski A: A pituitary-derived MEG3 isoform functions as a growth suppressor in tumor cells. J Clin Endocrinol Metab 88: 5119-5126, 2003.

10. Zhou X, Ji G, Ke X, Gu H, Jin W and Zhang G: MiR-141 inhibits gastric cancer proliferation by interacting with long noncoding RNA MEG3 and down-regulating E2F3 expression. Dig Dis Sci 60: 3271-3282, 2015

11. Yan J, Guo X, Xia J, Shan T, Gu C, Liang Z, Zhao W and Jin S: MiR-148a regulates MEG3 in gastric cancer by targeting DNA methyltransferase 1. Med Oncol 31: 879, 2014.

12. Braconi C, Kogure T, Valeri N, Huang N, Nuovo G, Costinean S, Negrini M, Miotto E, Croce CM and Patel T: microRNA-29 can regulate expression of the long non-coding RNA gene MEG3 in hepatocellular cancer. Oncogene 30: 4750-4756, 2011.

13. Li L, Xu-Monette ZY, Ok CY, Tzankov A, Manyam GC, Sun R, Visco C, Zhang M, Montes-Moreno S, Dybkaer K, et al: Prognostic impact of c-Rel nuclear expression and REL amplification and crosstalk between c-Rel and the p53 pathway in diffuse large B-cell lymphoma. Oncotarget 6: 23157-23180, 2015. 
14. Dettman EJ, Simko SJ, Ayanga B, Carofino BL, Margolin JF, Morse HC III and Justice MJ: Prdm14 initiates lymphoblastic leukemia after expanding a population of cells resembling common lymphoid progenitors. Oncogene 30: 2859-2873, 2011.

15. Cimmino A, Calin GA, Fabbri M, Iorio MV, Ferracin M, Shimizu M, Wojcik SE, Aqeilan RI, Zupo S, Dono M, et al miR-15 and miR-16 induce apoptosis by targeting BCL2. Proc Natl Acad Sci USA 102: 13944-13949, 2005.

16. Ul Hussain M: Micro-RNAs (miRNAs): Genomic organisation, biogenesis and mode of action. Cell Tissue Res 349: 405-413, 2012.

17. Wang D, Qiu C, Zhang H, Wang J, Cui Q and Yin Y: Human microRNA oncogenes and tumor suppressors show significantly different biological patterns: From functions to targets. PLoS One 5: 5, 2010

18. Yu X, Luo A, Liu Y, Wang S, Li Y, Shi W, Liu Z and Qu X: MiR-214 increases the sensitivity of breast cancer cells to tamoxifen and fulvestrant through inhibition of autophagy. Mol Cancer 14: 208, 2015.

19. Li QQ, Xie YK, Wu Y, Li LL, Liu Y, Miao XB, Liu QZ, Yao KT and Xiao GH: Sulforaphane inhibits cancer stem-like cell properties and cisplatin resistance through miR-214-mediated downregulation of c-MYC in non-small cell lung cancer. Oncotarget: Jan 5, 2017 (Epub ahead of print). doi: 10.18632/ oncotarget.14512.

20. Zou ZJ, Fan L, Wang L, Xu J, Zhang R, Tian T, Li JY and Xu W: miR-26a and miR-214 down-regulate expression of the PTEN gene in chronic lymphocytic leukemia, but not PTEN mutation or promoter methylation. Oncotarget 6: 1276-1285, 2015.

21. Zhang J, Liu J, Xu X and Li L: Curcumin suppresses cisplatin resistance development partly via modulating extracellular vesicle-mediated transfer of MEG3 and miR-214 in ovarian cancer. Cancer Chemother Pharmacol 79: 479-487, 2017.

22. Susin SA, Lorenzo HK, Zamzami N, Marzo I, Snow BE, Brothers GM, Mangion J, Jacotot E, Costantini P, Loeffler M, et al: Molecular characterization of mitochondrial apoptosisinducing factor. Nature 397: 441-446, 1999.

23. Loeffler M, Daugas E, Susin SA, Zamzami N, Metiy Nieminen AL, Brothers G, Penninger JM and Kroemer Dominant cell death induction by extramitochondrially tar apoptosis-inducing factor. FASEB J 15: 758-767, 2001

24. Miramar MD, Costantini P, Ravagnan L, Saraiv Brothers G, Penninger JM, Peleato ML Susin SA: NADH oxidase activity of mitoc inducing factor. J Biol Chem 276: 16391-1638

25. Lu J, Chen J, Xu N, Wu J, Kang Y, Cheng M, Shao Z, et al: Activation of of human lung cancer cells un Toxicol Lett 258: 227-236, 2016

26. Wu M, Xu LG, Su T, Tian Y, Zhai Z and Shu HB: AMID is a p53-inducible gene downregulated in tumors. Oncogene 23: 6815-6819, 2004.

27. Tao YF, Xu LX, Lu J, Hu SY, Fang F, Cao L, Xiao PF, Du XJ, Sun LC, Li ZH, Wang NN, et al: Early B-cell factor 3 (EBF3) is a novel tumor suppressor gene with promoter hypermethylation in pediatric acute myeloid leukemia. J Exp Clin Cancer Res 34 4,2015

28. Liu J, Ma L, Li C, Zhang Z, Yang G and Zhang W: Tumortargeting TRAIL expression mediated by miRNA response elements suppressed growth of uveal melanoma cells. Mol Oncol 7: 1043-1055, 201

29. Mou H, Zheng Y, Zhao P, Bao H, Fang W and Xu N: Celastrol induces apoptosis in non-small-cell lung cancer A549 cells through activation of mitochondria- and Fas/FasL-mediated pathways. Toxicol In Vitro 25: 1027-1032, 2011.

30. Burkhardt B, Reiter A, Landmann E, Lang P, Lassay L, Dickerhoff R, Lakomek M, Henze G and von Stackelberg A: Poor outcome for children and adolescents with progressive disease or relapse of lymphoblastic lymphoma: A report from the Berlin-Frankfurt-Muenster group. J Clin Oncol 27: 3363-3369, 2009.

31. Astuti D, Latif F, Wagner K, Gentle D, Cooper WN, Catchpoole D, Grundy R, Ferguson-Smith AC and Maher ER: Epigenetic alteration at the DLK1-GTL2 imprinted domain in human neoplasia: Analysis of neuroblastoma, phaeochromocytoma and Wilms tumour. Br J Cancer 92: 1574-1580, 2005.

32. Wang P, Ren Z and Sun P: Overexpression of the long noncoding RNA MEG3 impairs in vitro glioma cell proliferation. J Cell Biochem 113: 1868-1874, 2012

33. Li J, Bian EB, He XJ, Ma CC, Zong G, Wang HL and Zhao B Epigenetic repression of long non-coding RNA MEG3 mediated by DNMT1 represses the 553 pathway in gliomas. Int J Oncol 48: 723-733, 2016.
34. Zhang X, Gejman R, Mahta A, Zhong Y, Rice KA, Zhou Y, Cheunsuchon P, Louis DN and Klibanski A: Maternally expressed gene 3, an imprinted noncoding RNA gene, is associated with meningioma pathogenesis and progression. Cancer Res 70: 2350-2358, 2010

35. Cai DX, Banerjee R, Scheithauer BW, Lohse CM, KleinschmidtDemasters BK and Perry A: Chromosome 1p and 14q FISH analysis in clinicopathologic subsets of meningioma: Diagnostic and prognostic implications. J Neuropathol Exp Neurol 60: 628-636, 2001

36. Zhang J, Yao T, Wang Y, Yu J, Liu Y and Lin Z: Long noncoding RNA MEG3 is downregulated in cervical cancer and affects cell proliferation and apoptosis by regulating miR-21. Cancer Biol Ther 17: 104-113, 2016.

37. Sun L, Li Y and Yang B: Downregulated long non-coding RNA MEG3 in breast cancer regulates proliferation, migration and invasion by depending on p53's transcriptional activity. Biochem Biophys Res Commun 478: 323-329, 2016.

38. Xia Y, He Z, Liu B, Wang P and Chen Y: Downregulation of Meg3 enhances cisplatin resistance of lung cancer cells through activation of the WNT/ $\beta$-catenin signaling pathway. Mol Med Rep 12: 4530-4537, 2015.

39. Chak WP, Lung RW, Tong JH, Chan SY, Lun SW, Tsao SW, Lo KW and To KF: Downregulation of long non-coding RNA MEG3 in nasopharyngeal carcinoma. Mol Carcinog 56: 1041-1054, 20

40. Liu LX, Deng W, Zhou XT, Chen RP, Xiang MQ, Guo YT, $\mathrm{Pu}$ ZJ, Li R, Wang GF and Wu LF. The mechanism of adenosinemediated activation of IncRNA MEG3 and its antitumor effects in human hepatoma cells. Int J Oncol 48: 421-429, 2016.

41. Peng R, Men J, Ma R, Wang Q, Wang Y, Sun Y and Ren J: miR-214 down-regulates ARL2 and suppresses growth and invasion of cervical cancer cells. Biochem Biophys Res Commun 484: 623-630, 2017.

i SJ, Li LL and Tu WB: MiR-214 negatively regulates proliferaand WNT/ $\beta$-catenin signaling in breast cancer. Eur Rev Med Pharmacol Sci 20: 5148-5154, 2016.

43. $\mathrm{Xu} \mathrm{Z}$ and Wang T: miR-214 promotes the proliferation and invasion of osteosarcoma cells through direct suppression of LZTS1. Biochem Biophys Res Commun 449: 190-195, 2014.

R. Bai F, Feng Y, Jiu M, Liu X, Bai F, Nie Y and Fan D: RNA-214 promotes peritoneal metastasis through regulating PTEN negatively in gastric cancer. Clin Res Hepatol Gastroenterol 40: 748-754, 2016.

Narducci MG, Arcelli D, Picchio MC, Lazzeri C, Pagani E, Sampogna F, Scala E, Fadda P, Cristofoletti C, Facchiano A, et al: MicroRNA profiling reveals that miR-21, miR486 and miR-214 are upregulated and involved in cell survival in Sézary syndrome. Cell Death Dis 2: e151, 2011.

46. Sharma T, Hamilton R and Mandal CC: miR-214: A potential biomarker and therapeutic for different cancers. Future Oncol 11: 349-363, 2015.

47. Ohyama M, Tsuchiya A, Kaku Y, Kanno T, Shimizu T, Tanaka A and Nishizaki T: Phosphatidylinositol derivatives induce gastric cancer cell apoptosis by accumulating AIF and AMID in the nucleus. Anticancer Res 35: 6563-6571, 2015.

48. Gong M, Hay S, Marshall KR, Munro AW and Scrutton NS: DNA binding suppresses human AIF-M2 activity and provides a connection between redox chemistry, reactive oxygen species, and apoptosis. J Biol Chem 282: 30331-30340, 2007.

49. Zhou Y, Zhong Y, Wang Y, Zhang X, Batista DL, Gejman R, Ansell PJ, Zhao J, Weng C and Klibanski A: Activation of p53 by MEG3 non-coding RNA. J Biol Chem 282: 24731-24742, 2007.

50. Ohiro Y, Garkavtsev I, Kobayashi S, Sreekumar KR, Nantz R, Higashikubo BT, Duffy SL, Higashikubo R, Usheva A, Gius D, et al: A novel p53-inducible apoptogenic gene, PRG3, encodes a homologue of the apoptosis-inducing factor (AIF). FEBS Lett 524: 163-171, 2002.

51. Ribarska T, Goering W, Droop J, Bastian KM, Ingenwerth M and Schulz WA: Deregulation of an imprinted gene network in prostate cancer. Epigenetics 9: 704-717, 2014.

52. Chunharojrith $P$, Nakayama Y, Jiang X, Kery RE, Ma J, De La Hoz Ulloa CS, Zhang X, Zhou Y and Klibanski A: Tumor suppression by MEG3 lncRNA in a human pituitary tumor derived cell line. Mol Cell Endocrinol 416: 27-35, 2015.

53. Hu D, Su C, Jiang M, Shen Y, Shi A, Zhao F, Chen R, Shen Z, Bao J and Tang W: Fenofibrate inhibited pancreatic cancer cells proliferation via activation of p53 mediated by upregulation of LncRNA MEG3. Biochem Biophys Res Commun 471: 290-295, 2016. 